\title{
Study of determining the fishing season for tiger grouper (Epinephelus fuscoguttatus) landed at Kutaraja Fishing Port, Banda Aceh
}

\author{
Alvi Rahmah ${ }^{1,3^{*}}$, Julyanur Sahputri ${ }^{1}$, Ratna Mutia Aprilla ${ }^{1,3}$, Makwiyah Chaliluddin ${ }^{1,3}$, and Sayyid Afdhal Elrahimi ${ }^{2,3}$ \\ ${ }^{1}$ Department of Fisheries Resources Utilization, Faculty of Marine and Fisheries, Universitas Syiah Kuala, Banda Aceh 23111, \\ Indonesia \\ ${ }^{2}$ Department of Marine Sciences, Faculty of Marine and Fisheries, Universitas Syiah Kuala, Banda Aceh 23111, Indonesia \\ ${ }^{3}$ Research Center for Marine and Fisheries, Universitas Syiah Kuala, Banda Aceh 23111, Indonesia
}

\begin{abstract}
The tiger grouper (Epinephelus fuscoguttatus) is a type of fish landed at the Kutaraja Fishing Port using handline. The production of tiger grouper from 2014 to 2019 fluctuated, so it is necessary to determine the right fishing season to make it easier for fishermen to carry out fishing operations for tiger grouper effectively. This research was conducted in July-August 2020, at Kutaraja Fishing Port. The primary data consists fishing trip, location of fishing ground, and total catch, the secondary data (time series data of tiger grouper catches on 2014-2019, as well as research-related literature). The data analysis consists of catch per unit effort (CPUE) analysis and time series analysis using the moving average method.The catch per unit effort (CPUE) of handline at Kutaraja Fishing Port tends to decrease every year. The highest CPUE occurred in 2015 (26.06 kg/trip) and the lowest in 2018 (0.25 kg/trip). The fishing season index of tiger grouper (Epinephelus fuscoguttatus) showed that fish can be caught throughout the year. The results showed that the peak season for tiger grouper landed at Kutaraja Fishing Port occurred in February (201.0\%), March $(127.2 \%)$, June $(161.0 \%)$, and July (146.1\%). Meanwhile, the fishing season index of $50 \%$ to $<100 \%$ includes the moderate season in January (75.0\%), August $(91.2 \%)$ and December $(84.3 \%)$, and the low season occurs in May (33, 6\%), September (31.3\%), October (19.9\%) and November (41.8\%) with the index value less than $50 \%$. In conclusion, the catch per unit effort (CPUE) of tiger grouper (Epinephelus fuscoguttatus) at Kutaraja Fishery Port in 2014-2019 fluctuated but tends to experience a significant decline, where the value ranged from $0.25 \mathrm{~kg} /$ trip to $26.06 \mathrm{~kg} /$ trip. The peak season for fishing of tiger grouper occurs in February, March, June, and July; moderate season in January, August, and December; and low season occurs in May, September, October, and November.
\end{abstract}

\section{Introduction}

The Kutaraja Fishing Port is the largest fishing port in Aceh Province. The fishing gear used at Kutaraja fishing port to catch tiger grouper is handline and longline. Tiger grouper (Epinephelus fuscoguttatus) is one of the important economic commodities and include a group of coral fish with a wide distribution throughout Indonesia [1]. Annual production of tiger grouper (Epinephelus fuscoguttatus) tends to decrease significantly. This can be seen from the total production of tiger grouper (Epinephelus fuscoguttatus) at Kutaraja Fishing Port in 2014 which was $3,075 \mathrm{~kg} /$ year and decreased in 2019 by $56 \mathrm{~kg} /$ year. This condition is thought to be influenced by the fishing methods, fishing effort (trip), damage aquatic environment, and fishing season $[2,3]$.

Fishing season information is used to determine the right time for carrying out fishing operations, where fishing activities without a clear fishing plan and target will lead to non-optimal profits [4]. Determining the appropriate fishing season for tiger grouper
(Epinephelus fuscoguttatus) is important to know so that fishermen can obtain optimal catches, minimize fishing operation costs, and maintain the availability of tiger grouper [5-7].

Research on the fishing season for tiger grouper (Epinephelus fuscoguttatus) at Kutaraja fishing port has never been carried out. This study discusses the period of the fishing season for tiger grouper (Epinephelus fuscoguttatus) which landed in Kutaraja Fishing Port. Based on the catch and the number of fishing trips per month, it is necessary to determine the appropriate fishing season for tiger grouper (Epinephelus fuscoguttatus) in order to reduce time losses in fishing, so that the catches obtained by fishermen can be more optimal.

\footnotetext{
* Corresponding author: alvi_rahmah@unsyiah.ac.id
} 


\section{Materials and methods}

\subsection{Site and time}

This research was conducted in August 2020 at the Kutaraja Fishing Port, Banda Aceh, Aceh Province.

\subsection{Sampling and measurements}

The data collection method in this study used purposive sampling. Determination of the number of samples as much as $10 \%$ of the total population studied [8]. The total population of fishermen is 231 people with $10 \%$ taking based on the size of fishing vessels at the Kutaraja Fishing Port, so the sample of respondents per ship is 22 respondents. Data was collected through interviews using a questionnaire.

This study uses primary data and secondary data. Primary data consists of the number of fishing trips, time of capture (in months), number of catches, and distance from fishing grounds. Meanwhile, secondary data regarding data production of tiger grouper during 20142019 and data on fishing trips for 2014-2019 were obtained from Marine and Fishery Resources Supervision Unit of Kutaraja Fishing Port.

\subsection{Data and analysis}

The analysis of the fishing season index conducted in this study aims to determine the time series analysis of monthly data on tiger grouper catches for 6 years followed by the calculation of the moving average. With the following formula [9] :

a) Compile monthly CPUE series (2014-2019)

Where :

$$
C P U E_{i}=\frac{c i}{f i}
$$

CPUE $=$ Catch per fishing effort year i ( $\mathrm{kg} /$ trip$)$

$\mathrm{i}=1,2,3, \ldots, \mathrm{n}$

$\mathrm{ci}=$ Catch year $\mathrm{i}(\mathrm{kg})$

$\mathrm{fi}=$ Attempt to catch year i (trip)

b) Compile a 12 month CPUEi moving average (RG)

Where:

$$
\mathrm{RGi}=\frac{1}{12}\left(\sum_{i=i-6}^{i+5} C P U E\right)
$$

$\mathrm{RGi}=12$-month moving average $\mathrm{i}$

CPUE $=$ CPUE of order $\mathrm{i}$

$\mathrm{i}=6,7,8-, \mathrm{n}-5$

c) Compile the i-month centered CPUE moving average value (RGPi)

Where:

$$
\mathrm{RGPi}=\frac{1}{2}\left(\sum_{i=i}^{i=1} R G i\right)
$$

$\mathrm{RGPi}=\mathrm{i}$-month centered CPUE moving average $\mathrm{RGi}=12$-month moving average $\mathrm{i}$

d) Compile the average ratio of the first month (RBi)

$$
\mathrm{RBi}=\frac{\text { CPUEi }}{\mathrm{RGPi}}
$$

Where:

$\mathrm{Rbi}=$ Average ratio of the $\mathrm{i}$-month

CPUEi $=$ CPUE month $\mathrm{i}$

$\mathrm{i}=$ month $6,7,8 \ldots, \mathrm{n}-5$ e) Compile the average value in an ixj matrix which is compiled for each month starting from July 2014 to June 2019, then the calculation is carried out:

1. Average ratio for the first month (RBBi)

Where:

$$
\mathrm{RBBi}=\frac{1}{n}\left(\sum_{i=1}^{n} R B i j\right)
$$

$\mathrm{RBBi}=$ Average $\mathrm{Rbij}$ for month $\mathrm{i}$

Rbij : Ratio of monthly average for matrix size ixj

2. Total monthly average ratio (JRB)

$$
\mathrm{JRBB}=\sum_{i=i}^{12} R B B i
$$

Where:

JRBB $=$ Total monthly average ratio

$\mathrm{RBBi}=$ Average $\mathrm{Rbij}$ for month $\mathrm{i}$

$\mathrm{i}=1,2,3, \ldots \ldots, 12$

3. Correction Factor (FK)

$$
\mathrm{FK}=\frac{1200}{\mathrm{JRBB}}
$$

Where:

$\mathrm{FK}=$ Correction Factor Value

$\mathrm{JRBB}=$ Total monthly average ratio

4. 1st Month Catching Season Index (IMPi)

$I M P i=R B B i x F K$

Where:

IMPI $=$ Fishing Season Index value i month

$\mathrm{RBBi}=$ Average ratio for month $\mathrm{i}$

Criteria for determining the fishing season :

IMP Value $=100 \%:$ Normal (Moderate season)

IMP Value $>100 \%$ : Catching Season (Peak

Season)

IMP $<100 \% \quad$ : Not fishing season (low season)

\section{Results and Disscussion}

\subsection{Trends in Catch Per Unit Effort (CPUE) Tiger Grouper (Epinephelus fuscoguttatus)}

The catch per unit effort (CPUE) can provide an overview of the abundance of fish resources in a waters. CPUE analysis can be considered as an indicator of whether fish stocks in these waters are still in good condition or have run out. CPUE analysis can be obtained by way of dividing the tiger grouper catches by fishing effort (fishing trip). The dominant of fishing gear used by fishermen at Kutaraja Fishing Portto catch tiger grouper is handline. The highest catch per effort (CPUE) was found in 2015 which was $26.06 \mathrm{~kg} /$ trip and the lowest in 2018 was $0.25 \mathrm{~kg} /$ trip which landed at Kutaraja Fishing Port tends to decrease every year, it can be seen in Table 1 below: 
Table 1. The CPUE value of tiger grouper during 2014-2019

\begin{tabular}{|c|c|c|c|}
\hline Year & Catch (Kg) & $\begin{array}{c}\text { Effort } \\
\text { (Trip) }\end{array}$ & CPUE(kg/trip) \\
\hline 2014 & 3.075 & 428 & 7.18 \\
\hline 2015 & 10.372 & 398 & 26.06 \\
\hline 2016 & 3.008 & 1.030 & 2.92 \\
\hline 2017 & 1.399 & 1,124 & 1.24 \\
\hline 2018 & 282 & 1.119 & 0.25 \\
\hline 2019 & 1.161 & 1,131 & 1.03 \\
\hline
\end{tabular}

The CPUE trend which shows a downward trend is an indirect indication of the occurrence of excessive utilization, on the contrary the CPUE trend which tends to increase indicates that resource utilization is still within safe limits and has the potential for further development [10]. Based on the results of research for the last 6 years, the production value of tiger grouper in Kutaraja Fishing Port tends to fluctuate, where in 20142015 fishing production increased by $237 \%$, then in 2015-2016 capture production decreased by $71 \%$, in 2015-2016 in 2016-2017 the catch production decreased by $53 \%$, in $2017-2018$ the catch production decreased by $80 \%$ and in 2018-2019 the catch production increased by $312 \%$.

Catching efforts have increased where the highest fishing effort occurred in 2019 as many as 1,131 trips and the lowest effort occurred in 2015 which only reached 398 trips. The average fishing effort in 20142019 was 5,230 trips. This is because fishermen who increase their fishing effort in the form of fishing trips occur because fishermen assume that the more fishing efforts they make will increase the production of their catch, but in fact, after research, the production of the catch has decreased. [11] states that several characteristics that can be used as benchmarks for a fishery towards a condition of more fishing effort are the time at sea being longer than usual, the size of the net being smaller than usual, followed by a decrease in catch per unit effort (CPUE), smaller fish sizes, and usually higher fishing costs.

The effort used to calculate the CPUE value is the number of fishing trips operating from the number of ships landing the catch of tiger grouper (Epinephelus fuscoguttatus) at Kutaraja Fishing Port for the last 6 years (2014-2019). The result shows that the CPUE of tiger grouper landed at Kutaraja Fishing Port for the last 6 years tends to decreasebecause there was a very high fishing effort in that year and the previous year (in 2018) thus reducing the catch per unit effort (CPUE).

The changes in CPUE value every year is due to a decrease in catches and the large burden of production costs compared to the profits obtained. This is in accordance with the research of [12] that a decrease in effort in the same year is not always followed by an increase in production and vice versa. This shows that the increase in the number of fishing efforts is not the only factor causing the decline in catches, but may be influenced by various factors such as environmental changes that can affect fish abundance. This happened because the number of fishing efforts made in those years could increase the level of competition between fishermen so that the catch also decreased. [13] states that the catch is influenced by the number and efficiency of the fishing unit, the length of operation and the availability of fish caught in addition to being influenced by internal and external factors.

The changes in the CPUE value each year are influenced by the addition or reduction of the number of trips (effort). The CPUE value is inversely proportional to the effort value, where each additional effort will reduce the catch per unit of effort (CPUE). This is because the resources will tend to decrease if the fishing effort carried out continues to increase [14]. The increase in the CPUE value indicates that with a decrease in the number of fishing efforts, there is an increase in catch per trip [15]. [16] stated that the addition of fishing effort that is not followed by an increase in the number of catches will reduce the CPUE value, this is supported by the research of [17] that the size of the trip does not guarantee the amount of production of the catch obtained is large. This can be an indicator that the utilization of fish resources in these waters is already high. [18] states that increasing efforts will lead to a decrease in fish biomass. This is also similar to the results of research by [19] in PPN Prigi which shows that CPUE continues to decline along with the increase in fishing efforts made.Resources will tend to decrease if the fishing effort carried out continues to increase. It is well known that CPUE is negatively correlated with catch effort. When the number of capture attempts is low, the CPUE is high, and vice versa when the number of trips is high, the CPUE decreases. This relationship forms the basis of a popular surplus production model in the discipline of fish stock studies, the Schaefer model assumes that CPUE decreases linearly, as fishing effort increases, therefore, the moving average method only considers changes in the actual CPUE during certain months. the number of boat trips differs consistently from other months. The correlation between CPUE and effort shows a negative relationship, namely the higher the effort, the lower the CPUE value.The negative correlation between CPUE and effort indicates that the productivity of fishing gear will decrease if effort increases [20].

\subsection{Fishing Season Index (FSI) of Tiger Grouper (Epinephelus fuscoguttatus)}

The results show that the peak season for fishing of tiger grouper occurs in February with an FSI of 201\%, and the low season in October with FSI of $19.9 \%$, it can be seen in Figure 1. 


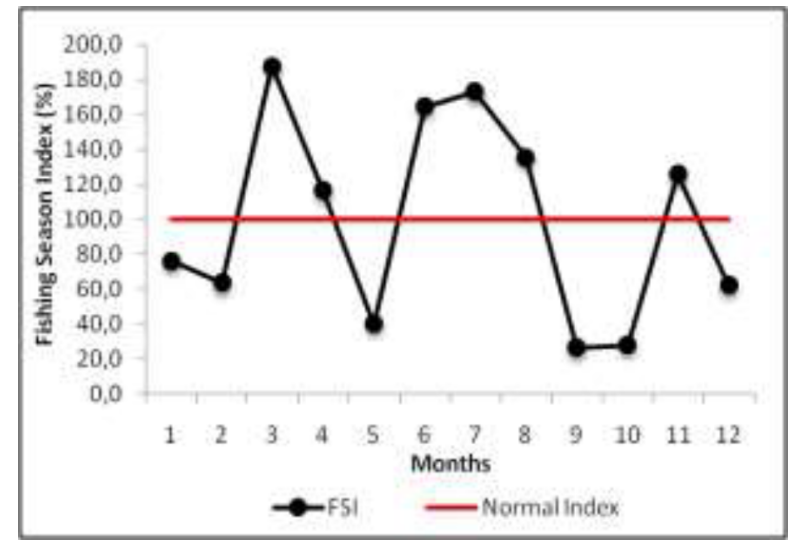

Fig. 1. The fishing season index (FSI) of tiger grouper at Kutaraja Fishing Port

Fishing Season Index (FSI) can be used in determining the right time to carry out fishing operations. Based on the result of FSI, it can be seen the trend of the fishing season so that the right time for fishing can be determined [5]. The FSI of tiger grouper (Epinephelus fuscoguttatus) based on research results for the last 6 years shows that tiger grouper can be caught throughout the year. [21] states that the value of the fishing season index can be used in determining the right time to carry out fishing operations.

Based on the criteria for determining the fishing season, the FSI that have a value greater than $100 \%$ are included in the peak season. The results of the FSIshow that the peak season for tiger grouper fishing occurs in February (201\%), March (127\%), June (161\%), and July (146\%); moderate fishing season occurs in January (75\%), August (91\%) and December (84\%), and the low season occurs in May (34\%), September (31\%), October $(20 \%)$ and November $(42 \%)$ with the FSI of less than $50 \%$. This is in accordance with research from [22] which found that the fishing season of grouper for ten months starts from January, February, March, May, June, July, August, September, November, and December with the peak season in March. March is the peak season for fishing of grouper, possibly due to low rainfall. This increases the opportunities for fishermen to carry out fishing operations. This is in accordance with the research of [23] which states that the fishing season index for reef fish shows that each species has its own fishing season and replaces each other every month.The results of interviews with fishermen said that the tiger grouper (Epinephelus fuscoguttatus) in Kutaraja Fishing Port is a fish whose existence is difficult to predict by fishermen, so that the catch of tiger grouper (Epinephelus fuscoguttatus) is relatively uncertain and fish that exist every year.

The caught of tiger grouper throughout the year can be related to the variability of oceanographic factors in the waters. The two most commonly associated oceanographic parameters are sea surface temperature and chlorophyll-a concentration [24]. According to [25] oceanographic parameters are one of the factors that greatly influence the variability of fish catches because temperature greatly affects the biological metabolism of fish.Judging from the physical effect, the surface temperature can cause upwelling (reversal of water mass) which brings nutrients to the surface and makes foraging places for fish. While chlorophyll-a is an indicator of primary productivity for fish, where the peak season for fishing of grouper is in February because in this month the rainfall is low, making it easier for fishing. It is suspected that high chlorophyll-a is caused by an upwelling process that causes an abundance of phytoplankton which resulted in the gathering of groupers.In general, there is a linear relationship between chlorophyll-a and grouper catches. When the amount of chlorophyll-a increases, it will increase the number of phytoplankton on the sea surface. That way the fish will look for places or locations that store a lot of phytoplankton, it is also suspected that there will be a decrease in sea surface temperature.

\section{Conclusions}

The catch per unit effort (CPUE) value of tiger grouper (Epinephelus fuscoguttatus) landed at Kutaraja Fishing Port based on 2014-2019 fluctuated but tended to experience a significant decline, where the highest CPUE occurred in 2015 with a value of $26.06 \mathrm{~kg} /$ trip and CPUE the lowest occurred in 2018 with a value of $0.25 \mathrm{~kg} /$ trip.

The Fishing Season Index (FSI) for tiger grouper (Epinephelus fuscoguttatus) landed in Kutaraja Fishing Port based on data for 2014 to 2019 ranging between $19.9 \%$ to $201.0 \%$. The peak season for fishing of tiger grouper occurs in February, March, June, and July; moderate season occurs in January, August and December, and the low season occurs in May, September, October and November with the FSI of less than $50 \%$.

\section{References}

1. S. Made, S. Fakhriyyah, A. Darawelalangi, ECSOFiM, 04, 9 (2017)

2. R. Kurnia, K. Suwardi, I. Muchsin, M. Boer, Buletin PSP, 19, 7 (2011)

3. Fauziyah, F. Agustriani, D.M. Situmorang, Y. Suteja, Fishing seasons of fish landed at Sungailiat Archipelago Fishing Port in Bangka Regency, in Environment, Energy, and Earth Sciences, E3S Web of Conferences 7-9 May 2018, Purwokerto, Indonesia (2018)

4. E. Hamka, M. Rais, J. Science and Technology Utilization of Fishery Resources, 3, 6 (2017)

5. M. Syahrir, M.S. Baskoro, Darmawan, E. Lubis, E.S. Wiyono, J. Ilmu Per. Trop, 13 (2010)

6. D. Simbolon, B. Wiryawan, P.I. Wahyuningrum, H. Wahyudi, Bul. PSP, 19 (2011)

7. J. S. Kekenusa, V.N.R. Warung, D. Hatidja, J. Ilm. Sains, 12 (2012)

8. S. Arikunto, Research Methodology A Proposal Approach (PT. Rineka Cipta, 2002)

9. A. Dajan, Introduction to Statistical Methods (Research Institute for Social Economic Information, 1983) 
10. Ministry of Marine Affairs and

Fisheries, Attachment to the decision of the Director General

of Capture Fisheries Number18/kep-djpt/2014 concerning Technical Guidelines for Indicator Assessment for Fisheries Management with an Ecosystem Approach (Ministry of Marine Affairs and Fisheries, 2014)

11. J. Widodo, Suadi, Management of Marine Fisheries Resources (Gadjahmada University, 2018)

12. B. S. Mujais, J. Agrikan, 9, 2 (2016)

13. D. Simanjuntak, Usman, T.E.Y. Sari, JOM UNRI, 3, 1 (2018)

14. B. Suswanto, Z. Anna, I. Gumilar, J. Perikanan Kelautan, 2, 1 (2015)

15. R. I. Wahju, Zulkarnain, K.P.S. Mara, PSP Bulletin Journal, 19, 1 (2011)

16. E. Nugraha, B. Koswara,Yuniarti, J. of Fisheries and Marine Affairs, 3, 1 (2012)

17. R. M. Aprilla, Mustaruddin, E.S. Wiyono, N. Zulbainarni. JTPK, 4, 1 (2013)

18. I. Nahib, Bioeconomic analysis of the impact of the presence of FADs on the sustainability of small tuna fisheries resources (a case study in the waters of Palabuhanratu Bay, Sukabumi Regency). (Thesis, Faculty of Fisheries and Marine Sciences, Bogor Agricultural University, 2008)

19. E. Nurdin, A. A. Taurusman, R. Yusfiandayani, J. Lit Fishing. Eng, 8, 1 (2012)

20. S. Aminah, J. of Fish Scientiae. 1, 2 (2011)

21. Ihsan, E. S. Wiyono, S. H. Wisudo, J. Haluan, J. of Mar. Fis, 5, 2 (2014)

22. Andriyeni, Zulkhasyni, Fishing Season for Grouper (Epinephelus sp.), (Research Results Report, Faculty of Agriculture, Universitas Prof. Dr. Hazairin, S.H, 2015)

23. E. Yuliana, M. Boer, A. Fahrudin, M.M. Kamal, E. Muttaqin, Indonesian Journal of Fisheries Research, 22, 1 (2016)

24. W. Kurniawan, J. Oseana, 40, 4 (2015)

25. Adnan, J. Amanisal PSP FPIK Unpati, 6, 1 (2010) 